\title{
A Novel Absorbent of Nano-Fe Loaded Biomass Char and Its Enhanced Adsorption Capacity for Phosphate in Water
}

\author{
Hongguang Zhou, Zhenmao Jiang, and Shiqiang Wei \\ College of Resources and Environment, Southwest University, Chongqing Key Laboratory of Agricultural Resources and Environment, \\ Key Laboratory of Eco-environments of Three Gorges Reservoir Region, Chongqing 400716, China
}

Correspondence should be addressed to Shiqiang Wei; sqwei@swu.edu.cn

Received 26 September 2013; Accepted 21 October 2013

Academic Editor: Tifeng Jiao

Copyright (C) 2013 Hongguang Zhou et al. This is an open access article distributed under the Creative Commons Attribution License, which permits unrestricted use, distribution, and reproduction in any medium, provided the original work is properly cited.

\begin{abstract}
A novel composite adsorbent of Fe loaded biomass char $(\mathrm{Fe}-\mathrm{BC})$ was fabricated to treat phosphorus in water. Fe-BC was prepared by a procedure including metal complex anion incorporation and precipitation with the pyrolysis char of corn straw as supporting material. The abundant porous structures of the as-prepared sample can be easily observed from its scanning electron microscopy (SEM) images. Observations by X-ray diffraction (XRD) and X-ray photoelectron spectroscopy (XPS) analyses show that inorganic nanoiron oxides deposited in the composite could be amorphous hydrous iron oxide $\alpha$-FeOOH. Adsorption of phosphate onto the Fe-BC composite and its precursor (BC) from aqueous solutions were investigated and discussed. The equilibrium adsorption data of phosphate was described by Langmuir and Freundlich models, and Langmuir isotherm was found to be better fitted than Freundlich isotherm. The maximum phosphate adsorption capacity for phosphate of $\mathrm{Fe}-\mathrm{BC}$ was as high as $35.43 \mathrm{mg} / \mathrm{g}$, approximately 2.3 times of $\mathrm{BC}$ at $25^{\circ} \mathrm{C}$. The adsorption kinetics data were better fitted by pseudo-second-order model and intraparticle diffusion model, indicating that the adsorption process was complex. The Fe-BC composite has been proved as an effective adsorbent of phosphate from aqueous solutions owing to its unique porous structures and the greater Lewis basicity of the $\alpha-\mathrm{FeOOH}$
\end{abstract}

\section{Introduction}

Phosphorus is considered as the main culprit of lake eutrophication [1]. Excess phosphorus will stimulate the algal blooms, causing deterioration of water quality [2]. In recent years, human activities dramatically increased the loads of phosphate in environment and its cycling rate on Earth, such as the production and application of a plenty of detergents, agricultural pesticides, and fertilizers [3]. The increased amount of phosphorus in water bodies poses greater potentials to the occurring of eutrophication. It has been reported that the red tide may occur at concentration of phosphorus higher than $0.03 \mathrm{mg} / \mathrm{L}$ in the lake (sea) [4].

Municipal wastewater may contain variety concentrations of phosphate ranging from 4 to $15 \mathrm{mg}-\mathrm{P} / \mathrm{L}$, and industrial wastewater (such as detergent manufacturing) may contain phosphate levels well in excess of $10 \mathrm{mg}-\mathrm{P} / \mathrm{L}$ [5]. Hence high effective methods for the removal of phosphate from wastewater need to be established. Traditional biological treatment of phosphorus has been proved to be highly variable due to its hard operation conditions [6]; thus discharge limits of phosphate were hardly matched depending only on this technology regardless of its high cost. Chemical precipitation technology has been wildly used in phosphate removal, usually with salts of iron (such as ferric chloride) [7-9], aluminum [10, 11], or lime [12]. However, the difficulties of excessive sludge handling and cost of added chemical materials would hinder its widespread application. Other effective phosphorus removal techniques such as ion exchange and electrodialysis also encountered difficulties of complicated management and high cost. Adsorption has been regarded as one of the most effective and economical methods for the removal of phosphorus. The key to the success of the method depends on the selection of adsorbent with high adsorption capacity. Numerous studies have been conducted for this purpose, such as activated alumina $[4,13]$, metal oxide hydroxides [14-21], hydrotalcite [22], palygorskite [23, 24], zeolite [13, 25-27], slag [28-31] and layered double hydroxides 
[32-36], as well as some waste materials such as red mud $[37,38]$, fly ash $[39,40]$, activated carbon $[41]$, modified wheat residues $[42,43]$, and peat [44].

Metal oxides are well known for their industrial applications as adsorbents, catalysts, and catalyst supports [45]. Hydrous iron oxides performance is highlighted in phosphate removal, and their adsorption capacity of phosphorus can reach up to $17 \mathrm{mg}-\mathrm{P} / \mathrm{g}$ [21]. This is mainly attributed to the formation of a stable bidentate ligand between ion oxides and phosphate. In particular, with the rapid development of nanotechnology, these kinds of metal oxide hydroxides have been prepared in nanoscale size by some researchers (Pan et al. 2009) [46]. Inorganic nanosize adsorbents showed high adsorption capacity due to their surface effect and the small size effect brought by the miniaturization of the particle size. However, conventional nanosized powder adsorbent has intrinsic drawback due to the difficulties of sedimentation and separation in such a slurry type system. Many efforts had been made to structure inorganic or organic materials with specific size, aperture, and morphology to overcome this limitation and extend its environmental applications, such as microspheres [47]. Precursor immersion-surface deposition method is another useful way to solve these problems; nanosize materials were well diffused into the precursor and then fixed by changing its chemical speciation.

There are various kinds of materials which can be used as precursor. Biomass char (BC) was considered as one of the best for its large surface areas, richness of inherent porous structures, and low cost. Biomass char can be obtained from biomass waste easily. Biomass wastes, derived from plants, are the most widely available renewable resource [48]. However, improper disposal of the increasing quantities of biomass waste may lead to various environmental issues. Agriculture produces large amount of biomass waste; for example, the annual production of corn straw reached about 0.22 billion tons only in China in 2009 [49], most of which were burnt directly outside in the field, causing atmospheric pollution, such as increased concentration of PM2.5, enhanced carbon emission, and $\mathrm{CO}_{2}$ concentration. The pyrolysis technology of biomass waste for bioenergy production had been considered as a promising method with higher energy conversion efficiency [50]. Recently, biomass waste pyrolysis for fuel gas or biooil also aroused some attention $[51,52]$.

As a byproduct of biomass waste pyrolysis, biomass char is only about $10-40 \%$ of the total production [53]. BC deriving from biomass waste pyrolysis has relatively high fixed-carbon content and inherent porous structures. It has been reported that $\mathrm{BC}$ obtained from biomass pyrolysis at $673-873 \mathrm{~K}$ has a surface area ranging from 80 to $450 \mathrm{~m}^{2} / \mathrm{g}$ [43-57]. Thus BC could be a potential absorbent for the removal of pollutants from water. Some studies have showed that biomass char could effectively adsorb many kinds of cation [53, 56] and anion [55-57], including phosphate anion. In order to make use of the advantages of abundant biomass based BC and the high adsorptive capacity of nanohydrous iron oxides, a novel composite adsorbent has been fabricated following the procedure of incorporation of hydrous iron oxides nanoparticles into the biochar from the pyrolysis of corn straw. The basic physicochemical properties of the composite and its precursor were characterized and their performances on phosphate adsorption were investigated. Adsorption isotherms and the kinetics of phosphate adsorption on the composite adsorbents were compared with its precursor and some similar absorbents from literature; the results show that the synthesized $\mathrm{Fe}-\mathrm{BC}$ is a promising absorbent for phosphate with remarkably high adsorption capacity.

\section{Experimental}

2.1. Materials and Methods. The raw biomass material was corn straw, a common agricultural waste, obtained from the countryside in Pengshui, Chongqing Province, China. Fresh corn straw was air-dried, cut into $1-4 \mathrm{~cm}$ small pieces, washed several times with deionized water, dried in a furnace at $333 \mathrm{~K}$ for $24 \mathrm{~h}$, and then being sieved to the particle diameters $1 \mathrm{~mm}$ after grated for pyrolysis. The phosphate solution was prepared by dissolving potassium dihydrogen phosphate $\left(\mathrm{KH}_{2} \mathrm{PO}_{4}\right)$ in deionized water. All chemicals used were of analytical grade.

2.1.1. Pyrolysis Experiments. The biochar samples were obtained by pyrolysis experiments, which were carried out in a packed bed reactor in flowing nitrogen atmosphere with a heating rate of $5^{\circ} \mathrm{C} / \mathrm{min}$. The final temperature was kept at $773 \mathrm{~K}$ and the solid residence time was about one hour.

2.1.2. Preparation of Nano-Fe Loaded Biochar. There are some basic groups on the BC as well as some acidic functional groups, which provide different adsorption active sites. The acidic functional groups may be more dominant than the basic groups on $\mathrm{BC}$. In our preliminary experiment, the mass of Fe loaded on the composite with $\mathrm{FeCl}_{4}{ }^{-}$is 3.7 times higher than the $\mathrm{FeCl}_{3}$. $\mathrm{BC}$ was weighed and immersed into $1 \mathrm{~mol} / \mathrm{L}$ $\mathrm{FeCl}_{4}{ }^{-}$aqueous solution (ratio of solid/solution is $1: 20$ ) at $\mathrm{pH}$ 2.0 under continuous stirring at room temperature for $24 \mathrm{~h}$. Then it was filtered by a $0.45 \mu \mathrm{m}$ microfiltration membrane to collect the upside solid and washed with deionized water until the filtrate becomes clear. The solid sample was transferred into a saturated $\mathrm{NaCl}$ solution, and the $\mathrm{pH}$ of the solution was maintained at 12.0 by adding $0.1 \mathrm{M} \mathrm{NaOH}$ solutions. During this process it was stirred by mixer, and the mixing time lasts for 30 minutes. After that, the sample was filtered off, washed thoroughly three times with deionized water, and then dried in a vacuum oven with a $-0.05 \mathrm{Kpa}$ vacuum at $60^{\circ} \mathrm{C}$ for $24 \mathrm{~h}$. The dried power was kept in a drier to make sure it was totally dried. The amount of Fe(III) loaded onto $\mathrm{BC}$ was then measured using atomic absorption spectroscopy (AAS) method [58].

2.2. Characterization Methods. The specific surface area of obtained biomass char (BC) and Fe loaded BC was analyzed by nitrogen adsorption using the Brunauer-Eett-Teller (BET) method with a Micromeritics ASAP-2010C automatic analyzer (Micromeritics Col Inc., Australia) at the temperature of $77 \mathrm{~K}$. Also, the char was also observed using Scanning 
Electron microscopy (SEM) analysis by SEM-EDS (S-3400N HITACHI Japan). X-ray powder diffraction (XRD) experiments were performed on a $\mathrm{D} / \mathrm{max}-3 \mathrm{~B}$ diffractometer with $\mathrm{Cu} \mathrm{K} \alpha$ irradiation at a scan rate of $0.02^{\circ} 2 \theta \mathrm{s}^{-1}$, to determine the identity of any phase present and its crystallite size. The composites were vacuum-dried at $30^{\circ} \mathrm{C}$ before characterization and ground for SEM and XRD analysis. XPS spectra of the $\mathrm{Fe}-\mathrm{BC}$ adsorbent before and after adsorption were performed by an X-ray photoelectron spectroscopy (Kratos AXIS Ultra, UK) with the monochromatic $\mathrm{Al} \mathrm{K} \alpha \mathrm{X}$-ray radiation $(1486.7 \mathrm{eV})$. The wide scans were conducted from 0 to $1400 \mathrm{eV}$ with pass energy of $160 \mathrm{eV}$. The high resolution scans were conducted according to the peak being examined with pass energy of $40 \mathrm{eV}$. The energy scale of the XPS spectra was calibrated with graphitic carbon as the reference at a binding energy of $284.8 \mathrm{eV}$ due to the surface contamination. The XPS spectra peaks of $\mathrm{Fe} 2 \mathrm{~s}$ were fitted using the XPS peak software.

2.3. Kinetic Adsorption Experiments. Simulation phosphate solutions were used throughout the adsorption tests. Initially, a stock solution was prepared by dissolving a certain amount of analytically pure $\mathrm{KH}_{2} \mathrm{PO}_{4}$ in deionized water. For adsorption experiments, the phosphate solutions with concentrations in the range of $1-100 \mathrm{mg} / \mathrm{L}$ were prepared by successive dilution of the stock solution with deionized water at room temperature. The supernatant solution was separated from the adsorbent by microfiltration membrane. Phosphate concentration in the supernatant was estimated spectrophotometrically by the molybdenum blue method; absorbance at $700 \mathrm{~nm}$ was monitored by UV-vis spectrophotometer.

Kinetic studies were carried out to establish the effect of contact time on the adsorption process and to quantify the adsorption rate. For kinetics adsorption experiments, each $0.05 \mathrm{~g}$ of adsorbents (BC, Fe-BC) was added into a series of flasks containing $50 \mathrm{~mL}$ phosphate solution $(20 \mathrm{mg}-\mathrm{P} / \mathrm{L})$, separately. The initial $\mathrm{pH}$ of the solution was maintained at 3.0 by adding $0.1 \mathrm{M} \mathrm{NaOH}$ or $0.1 \mathrm{M} \mathrm{HCl}$ solutions. The flasks were placed in a thermostatic shaker at $25^{\circ} \mathrm{C}$. At given time, each one of the flasks was taken out and immediately filtered by a $0.45 \mu \mathrm{m}$ microfiltration membrane to collect the filtrate and then the concentration of residual phosphate in the filtrate was determined by the method mentioned above.

2.4. Equilibrium Adsorption Experiments. For the equilibrium adsorption experiments, each $0.05 \mathrm{~g}$ of absorbents was added into a series of flasks containing $50 \mathrm{~mL}$ solution with phosphate concentration ranging from 1 to $100 \mathrm{mg}-\mathrm{P} / \mathrm{L}$. The flasks were then sealed and put in a thermostatic shaker at various constant temperatures and shaken at the $120 \mathrm{rpm}$ for $240 \mathrm{~min}$. Then the solution in the flasks was filtered and the phosphate concentration in the filtrate was measured. The phosphate absorbed at equilibrium was calculated using the following equation:

$$
Q=\frac{V\left(C_{0}-C_{e}\right)}{m},
$$

where $Q(\mathrm{mg} / \mathrm{g})$ is the amount of phosphate adsorbed, $V(\mathrm{~mL})$ is the volume of the solution, $C_{0}$ and $C_{e}(\mathrm{mg} / \mathrm{L})$ are the initial

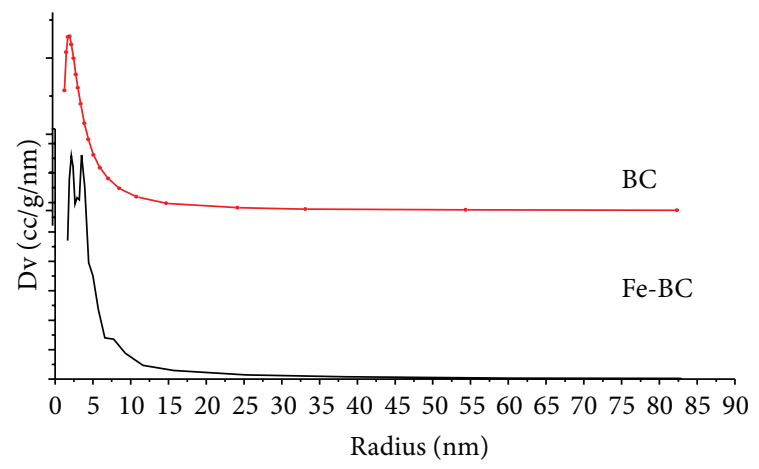

Figure 1: The pore size distribution of samples BC and Fe-BC.

and equilibrium concentrations of phosphate, respectively, and $m(\mathrm{~g})$ is the weight of adsorbent.

\section{Results and Discussion}

3.1. Characterization of BC Samples. The BC sample with very high BET surface area $\left(434.7 \mathrm{~m}^{2} / \mathrm{g}\right)$ and narrow pore size distribution (Figure 1), its average pore diameter is about $3.5 \mathrm{~nm}$. It may provide very good adsorption capacity and modified potentialities. The loaded treatment may decrease the BET surface area of composite which is only $18.71 \mathrm{~m}^{2} / \mathrm{g}$. As suggested, the preloaded nano-Fe particles would block some inner pores or make the pores narrower. Similar result was also reported by Shi concerning the effect of Fe(III) loadings on the pore volume and surface area of the resulting hybrid [58]. The mass of $\mathrm{Fe}$ in hybrid treated by $\mathrm{FeCl}_{4}{ }^{-}$is about $4.53 \%$. And the curve of average pore diameter performs a bimodal distribution, which means that the loaded treatment changed the structure and property. Incorporation of nanoFe into $\mathrm{BC}$ also altered its surface and textural morphology as shown by the SEM images in Figure 2. With different magnification $(\times 600$ and $\times 3000)$, different surface and structure can be seen clearly. The more irregular fragmented structure and pore structure of $\mathrm{BC}$ sample may contribute to its high surface area and pore volume.

As shown in Figure 3, there are no obvious peaks in the $\mathrm{XRD}$ patters which indicated that the iron oxides in the samples existed as amorphous state.

3.2. Adsorption Kinetics. The adsorption kinetics curves of phosphate adsorption on $\mathrm{BC}$ and $\mathrm{Fe}-\mathrm{BC}$ are shown in Figure 4, which may reflect the differences of adsorption rates and their rate control steps. The adsorption curves of $\mathrm{BC}$ and $\mathrm{Fe}-\mathrm{BC}$ go as the same tendency; they rise sharply at the first $5 \mathrm{~min}$ and tend to be gentle after 60 and $120 \mathrm{~min}$, respectively, which means that the adsorption speed is not constant during the whole process and the adsorption equilibrium time on $\mathrm{BC}$ is shorter than that on Fe-BC. But the $y$ value of $\mathrm{BC}$ at the equilibrium condition is lower than that of $\mathrm{Fe}-\mathrm{BC}$, indicating that the adsorption capacity of $\mathrm{BC}$ is lower than Fe-BC.

Four kinetic models were adopted to describe the adsorption process. The pseudo-first-order kinetic model has been widely used to predict sorption kinetics. The adsorption rate 

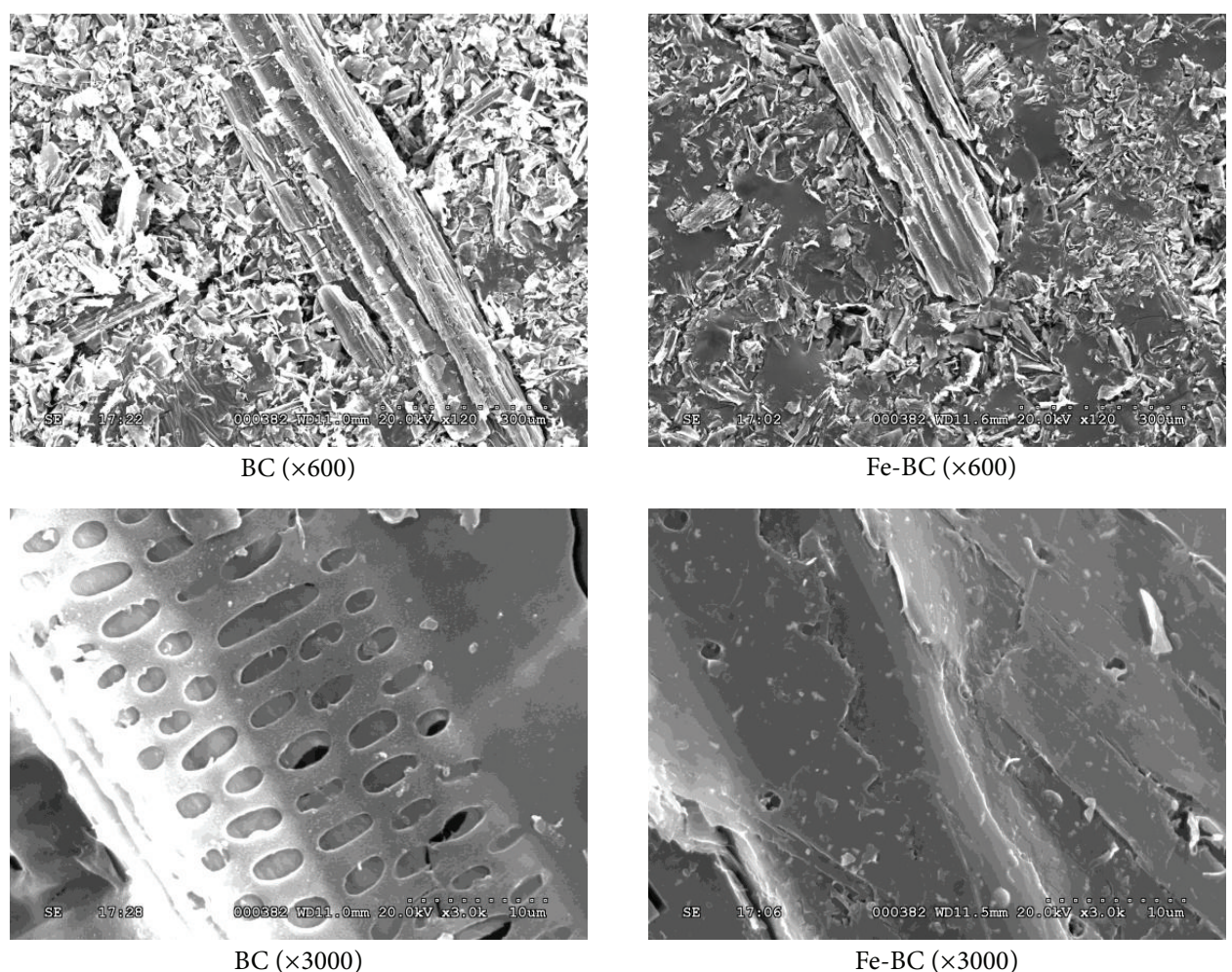

FIgure 2: SEM images of samples BC and Fe-BC.

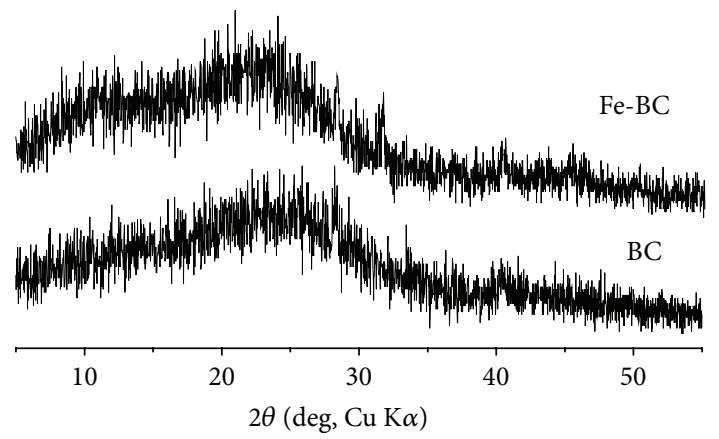

Figure 3: XRD diffraction pattern of BC and Fe-BC.

is proportional to the concentration of adsorbate. It can be used to describe the simple surface physical absorption. The model is defined as

$$
\ln \left(Q_{e}-Q_{t}\right)=\ln Q_{e}-k_{1} t
$$

The pseudo-second-order equation assumed that the adsorption mechanism was dominant by chemisorption. The adsorption rate is proportional to square of adsorbate concentration. The pseudo-second-order equation can be expressed as

$$
\frac{t}{Q_{t}}=\frac{1}{k_{2} Q_{e}^{2}}+\frac{t}{Q_{e}},
$$

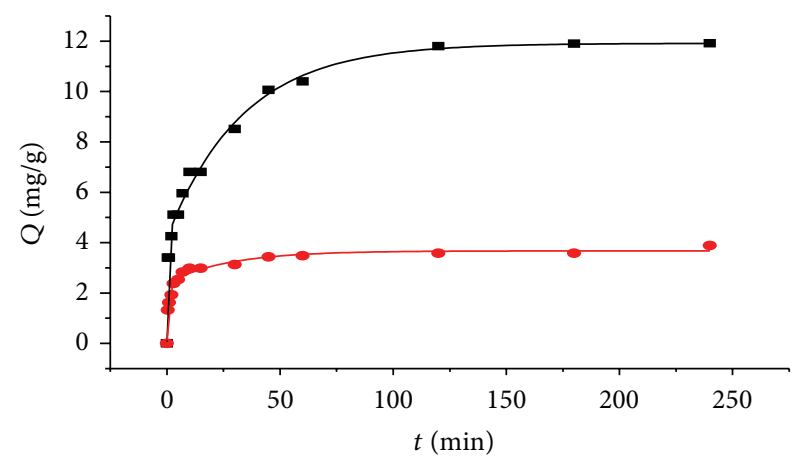

- $\mathrm{Fe}-\mathrm{BC}$

- $\mathrm{BC}$

FIgURE 4: The variation of adsorption capacity with adsorption time for phosphate on samples $\mathrm{BC}$ and $\mathrm{Fe}-\mathrm{BC}\left(T=25^{\circ} \mathrm{C}\right.$; adsorbent dose $=1 \mathrm{~g} / \mathrm{L} ;$ phosphate concentration $=20 \mathrm{mg} / \mathrm{L}$, and $\mathrm{pH}=3$ ).

where $k_{1}\left(\min ^{-1}\right)$ and $k_{2}$ are the pseudo-first-order rate constant and the pseudo-second-order rate constant, respectively, reflecting the adsorption rate change along with the concentration change. The results are showed in Table 1.

Compared with pseudo-second-order kinetic, the experimental $Q_{e, \exp }$ values of first-order kinetic do not well agree with the calculated $Q_{e, \text { cal }}$ values obtained from the curve plots, suggesting that the adsorption process is not maintained by simple surface physical absorption, and some other adsorption mechanisms were involved. 
TABle 1: Pseudo-first-order and Pseudo-second-order adsorption kinetic constants of samples BC and Fe-BC.

\begin{tabular}{lccccccccc}
\hline \multirow{2}{*}{ Samples } & \multirow{2}{*}{$Q_{e, \text { exp }}(\mathrm{mg} / \mathrm{g})$} & \multicolumn{3}{c}{ Pseudo-first-order model } & \multicolumn{4}{c}{ Pseudo-second-order model } \\
& & $Q_{e, \text { al }}(\mathrm{mg} / \mathrm{g})$ & $k_{1}\left(\mathrm{~min}^{-1}\right)$ & $R^{2}$ & S.D. (\%) & $Q_{e, \text { cal }}(\mathrm{mg} / \mathrm{g})$ & $k_{2}\left(\mathrm{gmg}^{-1} \mathrm{~min}^{-1}\right)$ & $R^{2}$ & S.D. (\%) \\
\hline BC & 3.58 & 3.34 & 0.508 & 0.905 & 16.22 & 3.52 & 0.211 & 0.967 & 9.51 \\
Fe-BC & 11.94 & 10.58 & 0.135 & 0.813 & 32.30 & 11.31 & 0.019 & 0.905 & 24.24 \\
\hline
\end{tabular}

TABLE 2: Liquid film diffusion model and Intraparticle diffusion constants for phosphate.

\begin{tabular}{lccccccccc}
\hline \multirow{2}{*}{ Samples } & \multirow{2}{*}{$Q_{e, \text { exp }}(\mathrm{mg} / \mathrm{g})$} & \multicolumn{3}{c}{ liquid film diffusion model } & \multicolumn{4}{c}{ Intraparticle diffusion model } \\
& & $Q_{e, \text { cal }}(\mathrm{mg} / \mathrm{g})$ & $R\left(\mathrm{~min}^{-1}\right)$ & $R^{2}$ & S.D. (\%) & $C$ & $K_{3}\left(\mathrm{mg} / \mathrm{gmin}^{1 / 2}\right)$ & $R^{2}$ & S.D. (\%) \\
\hline $\mathrm{C}$ & 3.58 & 3.34 & 0.508 & 0.905 & 16.22 & 1.70 & 0.271 & 0.770 & 25.52 \\
$\mathrm{BC}-\mathrm{Fe}$ & 11.94 & 10.58 & 0.135 & 0.813 & 32.30 & 2.93 & 1.025 & 0.975 & 20.56 \\
\hline
\end{tabular}

Generally, the process of the adsorbate adsorbed by adsorbent can be divided into four steps: firstly, adsorbate molecules transferred to the nearby adsorbent from solution; secondly, adsorbate molecules diffusion through the liquid film up to the surface of absorbent particles, this step usually was called external diffusion or mass transfer; thirdly, adsorbate molecules diffused through the absorbent particles and reached the inner side; this step is usually called intraparticle diffusion or diffusion; fourthly, adsorbate molecules were attracted at the active sites in the interior of the particles. Step one and four were not the rate-controlling steps due to their happening so fast. And the kinetics of the adsorption will be governed either by diffusion or by a mass transfer mechanism depending on which of the above steps is the slowest. Hence, in this study, two models were investigated to find out the rate-controlling step of the adsorption process.

Intraparticle diffusion model is based on the theory proposed by Weber and Morris [60]. It was used to identify the diffusion mechanism. According to this theory,

$$
Q_{t}=k_{3} \sqrt{t}+C,
$$

where $k_{3}$ is the intra-particular diffusion rate constant $\left(\mathrm{mg} \mathrm{g}^{-1} \mathrm{~min}^{-1 / 2}\right)$. If intraparticle diffusion is rate-limited, the plots of adsorbates uptake $Q_{t}$ versus the square root of time $\left(t^{1 / 2}\right)$ would result in a linear relationship. $k_{3}$ and $C$ values can be obtained from these plots.

The result of $Q_{t}$ versus $t^{1 / 2}$ is shown in Table 2. In diffusion model, the first step is the mass transfer of adsorbates molecule from the bulk solution to the adsorbent surface and second stage is the intraparticle diffusion on samples.

Liquid film diffusion model is based on the theory proposed by Boyd et al. [61]. It was also used to identify the diffusion mechanism and find out which step is the ratecontrolling step. According to this theory,

$$
\log (1-F)=\frac{R}{2.303} t
$$

where $F$ represents the degree of exchange of adsorbate which was adsorbed onto the particles and can be described as $Q_{t} / Q_{e}, R$ is a constant about the particle characters and it can be described as $R=3 D^{l} / r_{0} \delta k, D^{l}$ is the diffusion constant in the liquid, $r_{0}$ is the radius of spherical adsorbent, $\delta$ is the thickness of liquid film, and $k$ is distribution efficient.
Normalized standard deviation (S.D.) (\%) is used to find the most applicable model that could describe the kinetic study of adsorption of phosphate on samples A and B. The normalized standard deviation (S.D.) (\%) was calculated using the following equation [62]:

$$
\text { S.D. }(\%)=\sqrt{\sum\left\{\frac{\left[\left(Q_{t, \exp }-Q_{t, \text { cal }}\right) / Q_{t, \exp }\right]^{2}}{N-1}\right\}},
$$

where $N$ is the number of data points, $Q_{t, \exp }$ is the experimental values, and $Q_{t, \text { cal }}$ is the calculated value by the above four models, respectively. According to the values of S.D. (\%) given in Tables 1 and 2, it is clear that pseudo-second-order equation is better in describing the adsorption kinetics of phosphate by samples BC and Fe-BC. And Fe-BC sample is better fitting intraparticle diffusion model than liquid film diffusion model while the carrier material $\mathrm{BC}$ shows the opposite result. However, the difference of S.D. values for liquid film diffusion model and Intra-particle diffusion model was not significant, indicating that both intra-particle diffusion and mass transfer were the rate controlling steps.

3.3. Adsorption Isotherm Models. Equilibrium adsorption curves of $\mathrm{BC}$ and $\mathrm{Fe}-\mathrm{BC}$ are showed in Figure 5. With the concentration of phosphate increasing, the equilibrium adsorption capacity $Q_{e}$ increased at the low concentration level and remained unchanged when the concentration is higher than a certain value.

Langmuir and Freundlich isotherms were applied to describe the relationship between the amount of phosphate absorbed on absorbent and its equilibrium concentration in aqueous solution. The Langmuir and Freundlich equations were listed in Table 3, where $k_{l}(\mathrm{~L} / \mathrm{mg})$ is Langmuir constants related to adsorption capacity and energy of adsorption and $k_{f}(\mathrm{mg} / \mathrm{g})$ and $n$ are the constants of the Freundlich isotherm that measure the adsorption capacity and intensity of adsorption, respectively. In Freundlich equation, $1 / n$ values between 0 and 1 indicated a good adsorption.

The equilibrium adsorption data was analyzed using the Langmuir and Freundlich models. The estimated adsorption constants with corresponding correlation coefficients $\left(R^{2}\right)$ are summarized in Table 3 . The results indicate that both models can be used to describe the adsorption isotherms, while the 
TABLE 3: Adsorption isotherm parameters of samples BC and Fe-BC.

\begin{tabular}{|c|c|c|c|c|c|c|}
\hline \multirow[t]{2}{*}{ Samples } & \multicolumn{3}{|c|}{$\begin{array}{l}\text { Langmuir isotherm model } \\
C_{e} / Q_{e}=1 /\left(Q_{\max } k_{l}\right)+C_{e} / Q_{\max }\end{array}$} & \multicolumn{3}{|c|}{$\begin{array}{l}\text { Freundlich isotherm model } \\
\lg Q_{e}=\lg k_{f}+n^{-1} \lg C_{e}\end{array}$} \\
\hline & $Q_{\max }(\mathrm{mg} / \mathrm{g})$ & $k_{l}(\mathrm{~L} / \mathrm{mg})$ & $R^{2}$ & $\begin{array}{c}k_{f} \\
(\mathrm{mg} / \mathrm{g})(\mathrm{L} / \mathrm{mg})^{1 / n}\end{array}$ & $n^{-1}$ & $R^{2}$ \\
\hline $\mathrm{BC}$ & 15.44 & 0.038 & 0.978 & 1.628 & 0.484 & 0.943 \\
\hline $\mathrm{Fe}-\mathrm{BC}$ & 35.43 & 0.091 & 0.985 & 6.045 & 0.388 & 0.968 \\
\hline
\end{tabular}

TABLE 4: Phosphate adsorption parameters of different waste materials.

\begin{tabular}{lccccc}
\hline Materials & Adsorption capacity $(\mathrm{mg} / \mathrm{g})$ & $k_{l}$ & $k_{f}$ & $n^{-1}$ & Reference \\
\hline Red mud & 0.58 & 146.39 & 0.632 & 4.281 & {$[38]$} \\
Wheat straw & 2.81 & 0.008 & 0.044 & 1.087 & {$[43]$} \\
ZnCl $_{2}$-activated coir pith carbon & 5.1 & 0.282 & 1.482 & 0.330 & {$[41]$} \\
Zeolite & 6.45 & 0.139 & 0.91 & 0.437 & {$[59]$} \\
Peat & 8.91 & 0.033 & 0.713 & 2.042 & {$[44]$} \\
Nano Fe loaded BC & 35.43 & 0.091 & 6.045 & 0.388 & This study \\
\hline
\end{tabular}

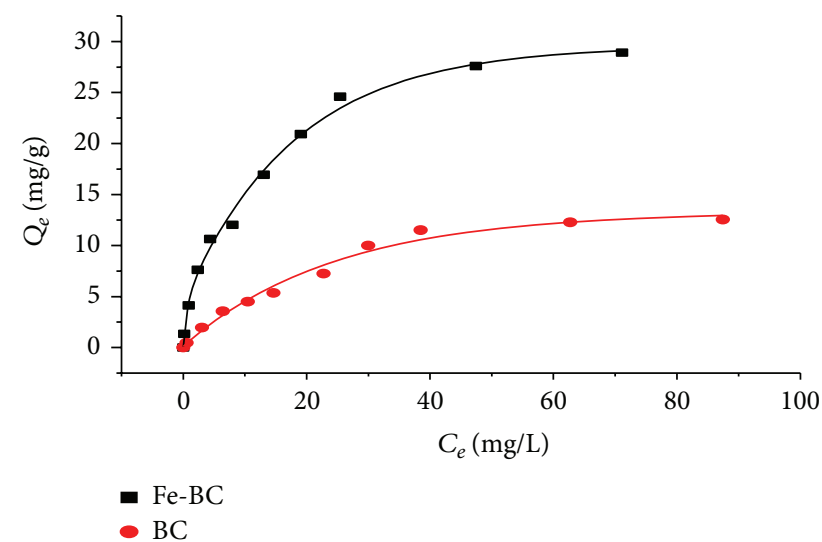

FIGURE 5: The adsorption capacity of phosphate onto samples BC and $\mathrm{Fe}-\mathrm{BC}$ at variety initial concentration $\left(T=25^{\circ} \mathrm{C}\right.$, adsorbent dose $=1 \mathrm{~g} / \mathrm{L}$, and $\mathrm{pH}=3$ ).

Langmuir model provides a better fitness than Freundlich model for phosphorus adsorption on BC absorbents. The maximum adsorption capacity obtained from Langmuir equation was $15.44 \mathrm{mg} / \mathrm{g}$ and $35.43 \mathrm{mg} / \mathrm{g}$ for BC and $\mathrm{Fe}-\mathrm{BC}$, respectively, indicating that incorporation of nanohydrous iron oxides into the biochar greatly increased the adsorption capacity for phosphate.

As shown in Figure 6, the XPS patters indicated that the iron oxides mainly exist in $\mathrm{FeOOH}$ forms. In addition, from XRD patters there is no fixed crystal, confirming that the iron oxides might be amorphous $\alpha-\mathrm{FeOOH}$, which is more active than other species [16]. Several signals of the iron oxide shell (peaks at 711.5 and $724.3 \mathrm{eV}$ [63] for $\mathrm{FeOOH}$ ) were observed. After adsorption, the banding energy of iron oxides is lower than before, and a new peak appeared at $712.8 \mathrm{eV}[64]$, suggesting that a kind of iron oxide was formed during the adsorption process.

The significant increase of adsorption capacity for $\mathrm{Fe}-\mathrm{BC}$ is probably due to the greater Lewis basicity of the $\mathrm{FeOOH}$ incorporated. The $\mathrm{pH}$ of the solution was maintained at 3.0,

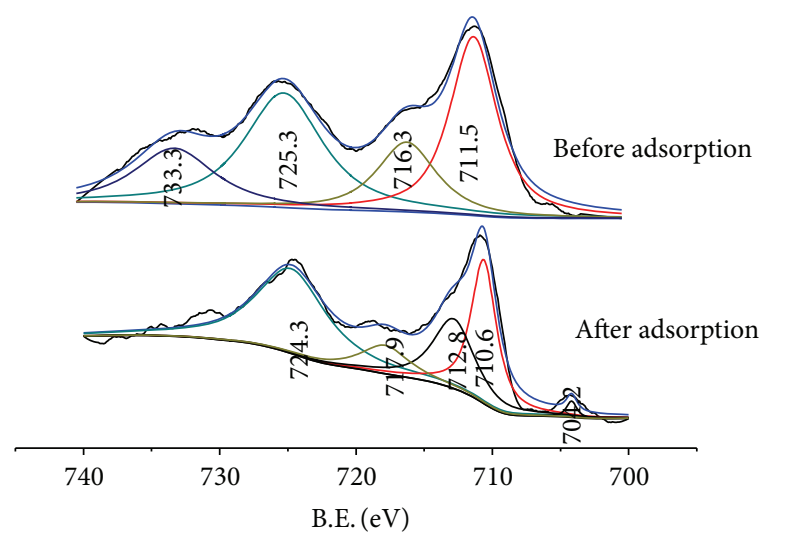

Figure 6: Fe 2s XPS spectra of BC-Fe before and after phosphate adsorption.

which was lower than the isoelectric point of $\mathrm{FeOOH}$ (8.7) [65], causing positively charged FeOOH surface. Therefore, it is not surprising that negative phosphate molecules are easily adsorbed on the $\mathrm{Fe}-\mathrm{BC}$ surface at a low $\mathrm{pH}$ range due to strong electrostatic attraction between phosphate and $\mathrm{FeOOH}$.

To compare the phosphate adsorption capacity of the synthesized composite in this study, the phosphate adsorption parameters of several other waste materials at similar conditions are cited from literature as shown in Table 4. It can be seen that the phosphate adsorption capacity of Fe$\mathrm{BC}$ was fairly large and its adsorption rate and intensity are higher than most of other materials. Thus, the Fe-BC was a potentially adsorbent to remove phosphate from waste water for its high adsorption capacity and rate.

\section{Conclusions}

The findings of this work indicated that the new ironcontaining $\mathrm{BC}$ material Fe-BC had great adsorption of phosphate ions. Adsorption fitted better to Langmuir isotherms 
than to Freundlich isotherm and the maximum phosphate adsorption for $\mathrm{Fe}-\mathrm{BC}$ was found to be $35.43 \mathrm{mg} / \mathrm{g}$ at $25^{\circ} \mathrm{C}$ which is approximately 2.3 times of BC. Kinetic data were well fit to a pseudo-second-order model and intraparticle diffusion model. The as-prepared Fe-BC is found to be effective adsorbent for the removal of phosphate from aqueous solutions because of its unique hierarchical porous structure and the greater Lewis basicity of the $\alpha$-FeOOH. This indicated that it is a potential adsorbent material for water treatment.

\section{Acknowledgments}

This research is supported by the National Major Science and Technology Projects for Water Pollution Control and Management (Grant no. 2012ZX07104-003), the Natural Scientific Foundation of China (Grants nos. 21207110 and 41171198), China Postdoctoral Science Foundation Funded Project (Grant no. 2013M540691), and the Fundamental Research Funds for the Central Universities (Grant no. XDJK2014C102).

\section{References}

[1] C. L. Schelske, "Eutrophication: focus on phosphorus," Science, vol. 324, no. 5928, p. 722, 2009.

[2] V. H. Smith, G. D. Tilman, and J. C. Nekola, "Eutrophication: impacts of excess nutrient inputs on freshwater, marine, and terrestrial ecosystems," Environmental Pollution, vol. 100, no. 13, pp. 179-196, 1999.

[3] P. J. A. Withers and H. P. Jarvie, "Delivery and cycling of phosphorus in rivers: a review," Science of the Total Environment, vol. 400, no. 1-3, pp. 379-395, 2008.

[4] S. Tanada, M. Kabayama, N. Kawasaki et al., "Removal of phosphate by aluminum oxide hydroxide," Journal of Colloid and Interface Science, vol. 257, no. 1, pp. 135-140, 2003.

[5] G. Akay, B. Keskinler, A. Çakici, and U. Danis, "Phosphate removal from water by red mud using crossflow microfiltration," Water Research, vol. 32, no. 3, pp. 717-726, 1998.

[6] G. Tchobanoglous and F. L. Burton, Wastewater Engineering, McGraw-Hill, 1991.

[7] R. L. McLaughlin and I. D. Brindle, "A laboratory-scale investigation into the use of powdered iron for in situ removal of phosphorus from treated sewage effluent with constructed wetlands," Water Quality Research Journal of Canada, vol. 36, no. 4, pp. 759-779, 2001.

[8] Y. Zhou, X.-H. Xing, Z. Liu et al., "Enhanced coagulation of ferric chloride aided by tannic acid for phosphorus removal from wastewater," Chemosphere, vol. 72, no. 2, pp. 290-298, 2008.

[9] N. Boujelben, J. Bouzid, Z. Elouear, M. Feki, F. Jamoussi, and A. Montiel, "Phosphorus removal from aqueous solution using iron coated natural and engineered sorbents," Journal of Hazardous Materials, vol. 151, no. 1, pp. 103-110, 2008.

[10] G. G. Timby, T. C. Danieli, R. W. McNew, and P. A. Moore Jr., "Polymer type and aluminum chloride affect screened solids and phosphorus removal from liquid dairy manure," Applied Engineering in Agriculture, vol. 20, no. 1, pp. 57-64, 2004.

[11] G. M. Ayoub, B. Koopman, and N. Pandya, "Iron and aluminum hydroxy (oxide) coated filter media for low-concentration phosphorus removal," Water Environment Research, vol. 73, no. 4, pp. 478-485, 2001.

[12] D. Seyhan and A. Erdincler, "Effect of lime stabilisation of enhanced biological phosphorus removal sludges on the phosphorus availability to plants," Water Science and Technology, vol. 48, no. 1, pp. 155-162, 2003.

[13] J.-W. Choi, S.-Y. Lee, S.-H. Lee, K.-B. Lee, D.-J. Kim, and S.-W. Hong, "Adsorption of Phosphate by amino-functionalized and co-condensed SBA-15," Water, Air and Soil Pollution, vol. 223, no. 5, pp. 2551-2562, 2012.

[14] A. Genz, A. Kornmüller, and M. Jekel, "Advanced phosphorus removal from membrane filtrates by adsorption on activated aluminium oxide and granulated ferric hydroxide," Water Research, vol. 38, no. 16, pp. 3523-3530, 2004.

[15] Y. Seida and Y. Nakano, "Removal of phosphate by layered double hydroxides containing iron," Water Research, vol. 36, no. 5, pp. 1306-1312, 2002.

[16] R. Chitrakar, S. Tezuka, A. Sonoda, K. Sakane, K. Ooi, and T. Hirotsu, "Phosphate adsorption on synthetic goethite and akaganeite," Journal of Colloid and Interface Science, vol. 298, no. 2, pp. 602-608, 2006.

[17] L. A. Rodrigues and M. L. C. P. da Silva, "Thermodynamic and kinetic investigations of phosphate adsorption onto hydrous niobium oxide prepared by homogeneous solution method," Desalination, vol. 263, no. 1-3, pp. 29-35, 2010.

[18] L. A. Rodrigues and M. L. C. P. da Silva, "An investigation of phosphate adsorption from aqueous solution onto hydrous niobium oxide prepared by co-precipitation method," Colloids and Surfaces A, vol. 334, no. 1-3, pp. 191-196, 2009.

[19] X. Yang, D. Wang, Z. Sun, and H. Tang, "Adsorption of phosphate at the aluminum (hydr)oxides-water interface: role of the surface acid-base properties," Colloids and Surfaces A, vol. 297, no. 1-3, pp. 84-90, 2007.

[20] B. Nowack and A. T. Stone, "Competitive adsorption of phosphate and phosphonates onto goethite," Water Research, vol. 40, no. 11, pp. 2201-2209, 2006.

[21] R. Chitrakar, S. Tezuka, A. Sonoda, K. Sakane, K. Ooi, and T. Hirotsu, "Selective adsorption of phosphate from seawater and wastewater by amorphous zirconium hydroxide," Journal of Colloid and Interface Science, vol. 297, no. 2, pp. 426-433, 2006.

[22] Z. Z. Huang, W. Q. Zhang, Y. D. Liu, H. J. TangBo, and Y. J. Zhu, "Adsorption characteristics of Hydrotalcite and the influencing factors," Water Treatment Technology, vol. 36, no. 8, pp. 49-52, 2010.

[23] A. Genz, A. Kornmüller, and M. Jekel, "Advanced phosphorus removal from membrane filtrates by adsorption on activated aluminium oxide and granulated ferric hydroxide," Water Research, vol. 38, no. 16, pp. 3523-3530, 2004.

[24] H. Ye, F. Chen, Y. Sheng, G. Sheng, and J. Fu, "Adsorption of phosphate from aqueous solution onto modified palygorskites," Separation and Purification Technology, vol. 50, no. 3, pp. 283290, 2006.

[25] J. Xie, C. J. Li, L. N. Chi, and D. Y. Wu, "Chitosan modified zeolite as a versatile adsorbent for the removal of different pollutants from water," Fuel, vol. 103, pp. 480-485, 2013.

[26] L. L. Gan, J. N. Zuo, B. M. Xie, P. Li, and X. Huang, "Zeolite $(\mathrm{Na})$ modified by nano-Fe particles adsorbing phosphate in rainwater runoff," Journal of Environmental Sciences, vol. 24, no. 11, pp. 1929-1933, 2012.

[27] P. Ning, H.-J. Bart, B. Li, X. Lu, and Y. Zhang, "Phosphate removal from wastewater by model-La(III) zeolite adsorbents," 
Journal of Environmental Sciences, vol. 20, no. 6, pp. 670-674, 2008.

[28] V. K. Jha, Y. Kameshima, A. Nakajima, and K. Okada, "Utilization of steel-making slag for the uptake of ammonium and phosphate ions from aqueous solution," Journal of Hazardous Materials, vol. 156, no. 1-3, pp. 156-162, 2008.

[29] J. Xiong, Z. He, Q. Mahmood, D. Liu, X. Yang, and E. Islam, "Phosphate removal from solution using steel slag through magnetic separation," Journal of Hazardous Materials, vol. 152, no. 1, pp. 211-215, 2008.

[30] L. Zeng, X. Li, and J. Liu, "Adsorptive removal of phosphate from aqueous solutions using iron oxide tailings," Water Research, vol. 38, no. 5, pp. 1318-1326, 2004.

[31] L. Johansson and J. P. Gustafsson, "Phosphate removal using blast furnace slags and opoka-mechanisms," Water Research, vol. 34, no. 1, pp. 259-265, 2000.

[32] N. I. Chubar, V. A. Kanibolotskyy, V. V. Strelko et al., "Adsorption of phosphate ions on novel inorganic ion exchangers," Colloids and Surfaces A, vol. 255, no. 1-3, pp. 55-63, 2005.

[33] R. Chitrakar, S. Tezuka, A. Sonoda, K. Sakane, K. Ooi, and T. Hirotsu, "Adsorption of phosphate from seawater on calcined MgMn-layered double hydroxides," Journal of Colloid and Interface Science, vol. 290, no. 1, pp. 45-51, 2005.

[34] J. Das, B. S. Patra, N. Baliarsingh, and K. M. Parida, "Adsorption of phosphate by layered double hydroxides in aqueous solutions," Applied Clay Science, vol. 32, no. 3-4, pp. 252-260, 2006.

[35] G. Zhang, H. Liu, R. Liu, and J. Qu, "Removal of phosphate from water by a Fe-Mn binary oxide adsorbent," Journal of Colloid and Interface Science, vol. 335, no. 2, pp. 168-174, 2009.

[36] O. R. Harvey and R. D. Rhue, "Kinetics and energetics of phosphate sorption in a multi-component $\mathrm{Al}(\mathrm{III})$-Fe(III) hydr(oxide) sorbent system," Journal of Colloid and Interface Science, vol. 322, no. 2, pp. 384-393, 2008.

[37] G. Akay, B. Keskinler, A. Çakici, and U. Danis, "Phosphate removal from water by red mud using crossflow microfiltration," Water Research, vol. 32, no. 3, pp. 717-726, 1998.

[38] W. Huang, S. Wang, Z. Zhu et al., "Phosphate removal from wastewater using red mud," Journal of Hazardous Materials, vol. 158, no. 1, pp. 35-42, 2008.

[39] N. M. Agyei, C. A. Strydom, and J. H. Potgieter, "The removal of phosphate ions from aqueous solution by fly ash, slag, ordinary Portland cement and related blends," Cement and Concrete Research, vol. 32, no. 12, pp. 1889-1897, 2002.

[40] J. Chen, H. Kong, D. Wu, Z. Hu, Z. Wang, and Y. Wang, "Removal of phosphate from aqueous solution by zeolite synthesized from fly ash," Journal of Colloid and Interface Science, vol. 300, no. 2, pp. 491-497, 2006.

[41] C. Namasivayam and D. Sangeetha, "Equilibrium and kinetic studies of adsorption of phosphate onto $\mathrm{ZnCl} 2$ activated coir pith carbon," Journal of Colloid and Interface Science, vol. 280, no. 2, pp. 359-365, 2004.

[42] X. Xu, B. Gao, W. Wang, Q. Yue, Y. Wang, and S. Ni, "Adsorption of phosphate from aqueous solutions onto modified wheat residue: characteristics, kinetic and column studies," Colloids and Surfaces B, vol. 70, no. 1, pp. 46-52, 2009.

[43] Z. Ma, Q. Li, Q. Yue et al., "Adsorption removal of ammonium and phosphate from water by fertilizer controlled release agent prepared from wheat straw," Chemical Engineering Journal, vol. 171, no. 3, pp. 1209-1217, 2011.

[44] J. B. Xiong and Q. Mahmood, "Adsorptive removal of phosphate from aqueous media by peat," Desalination, vol. 259, no. 1-3, pp. 59-64, 2010.
[45] H. Thakuria, B. M. Borah, and G. Das, "Macroporous metal oxides as an efficient heterogeneous catalyst for various organic transformations-a comparative study," Journal of Molecular Catalysis A, vol. 274, no. 1-2, pp. 1-10, 2007.

[46] B. Pan, J. Wu, B. Pan et al., "Development of polymer-based nanosized hydrated ferric oxides (HFOs) for enhanced phosphate removal from waste effluents," Water Research, vol. 43, no. 17, pp. 4421-4429, 2009.

[47] J. Dai, H. Yang, H. Yan, Y. Shangguan, Q. Zheng, and R. Cheng, "Phosphate adsorption from aqueous solutions by disused adsorbents: chitosan hydrogel beads after the removal of copper(II)," Chemical Engineering Journal, vol. 166, no. 3, pp. 970-977, 2011.

[48] A. V. Esin and E. P. Ayse, "Preparation and characterization of pyrolytic chars from different biomass samples," Journal of Analytical and Applied Pyrolysis, vol. 98, pp. 29-36, 2012.

[49] Y. Liang, L. Y. Liang, and F. Y. Xu, "The study of corn straw liquefaction technology," Anhui Agricultural Sciences, vol. 37, no. 27, pp. 13428-13429, 2009.

[50] H. Qinglan, W. Chang, L. Dingqiang, W. Yao, L. Dan, and L. Guiju, "Production of hydrogen-rich gas from plant biomass by catalytic pyrolysis at low temperature," International Journal of Hydrogen Energy, vol. 35, no. 17, pp. 8884-8890, 2010.

[51] F. Abnisa, W. M. A. W. Daud W.M.A. Wan, W. N. W. Husin, and J. Sahu, "Utilization possibilities of palm shell as a source of biomass energy in Malaysia by producing bio-oil in pyrolysis process," Biomass and Bioenergy, vol. 35, no. 5, pp. 1863-1872, 2011.

[52] H. Y. Zhang, J. Zheng, R. Xiao et al., "Co-catalytic pyrolysis of biomass and waste triglyceride seed oil in a novel fluidized bed reactor to produce olefins and aromatics integrated with selfheating and catalyst regeneration processes," RSC Advances, vol. 17, pp. 5769-5774, 2013.

[53] F. Peng, P. W. He, Y. Luo, X. Lu, Y. Liang, and J. Fu, "Adsorption of phosphate by biomass char deriving from fast pyrolysis of biomass waste," Clean Soil, Air, Water, vol. 40, no. 5, pp. 493498, 2012.

[54] Y. Chun, G. Sheng, G. T. Chiou, and B. Xing, "Compositions and sorptive properties of crop residue-derived chars," Environmental Science and Technology, vol. 38, no. 17, pp. 4649-4655, 2004.

[55] Y.-N. Chen, L.-Y. Chai, and Y.-D. Shu, "Study of arsenic(V) adsorption on bone char from aqueous solution," Journal of Hazardous Materials, vol. 160, no. 1, pp. 168-172, 2008.

[56] E. L. K. Mui, W. H. Cheung, M. Valix, and G. McKay, "Dye adsorption onto char from bamboo," Journal of Hazardous Materials, vol. 177, no. 1-3, pp. 1001-1005, 2010.

[57] G. Sheng, Y. Yang, M. Huang, and K. Yang, "Influence of pH on pesticide sorption by soil containing wheat residue-derived char," Environmental Pollution, vol. 134, no. 3, pp. 457-463, 2005.

[58] Z. L. Shi, F. M. Liu, and S. H. Yao, "Adsorptive removal of phosphate from aqueous solutions using activated carbon loaded with Fe(III) oxide," New Carbon Materials, vol. 26, no. 4, pp. 299-306, 2011.

[59] K. Sakadevan and H. J. Bavor, "Phosphate adsorption characteristics of soils, slags and zeolite to be used as substrates in constructed wetland systems," Water Research, vol. 32, no. 2, pp. 393-399, 1998.

[60] W. J. Weber and J. C. Morris, "Advances in water pollution research: removal of biologically resistant pollutant from waste water by adsorption," in Proceedings of the International Conference on Water Pollution Symposium, vol. 2, pp. 231-266, Pergamon Press, Oxford, UK, 1962. 
[61] G. E. Boyd, A. W. Adamson, and L. S. Myers Jr., "The exchange adsorption of ions from aqueous solutions by organic zeolites. II. Kinetics," Journal of the American Chemical Society, vol. 69, no. 11, pp. 2836-2848, 1947.

[62] J. Zhou, S. Yang, and J. Yu, "Facile fabrication of mesoporous $\mathrm{MgO}$ microspheres and their enhanced adsorption performance for phosphate from aqueous solutions," Colloids and Surfaces A, vol. 379, no. 1-3, pp. 102-108, 2011.

[63] B. J. Tan, K. J. Klabunde, and P. M. A. Sherwood, "X-ray photoelectron spectroscopy studies of solvated metal atom dispersed catalysts. Monometallic iron and bimetallic ironcobalt particles on alumina," Chemistry of Materials, vol. 2, no. 2, pp. 186-191, 1990.

[64] V. V. Nemoshalenko, V. V. Didyk, V. P. Krivitskii, and A. I. Senekevich, "Study of the Change State of Atoms in Iron, Cobalt and Nickel Phosphides," Zhurnal Neorganicheskoi Khimii, vol. 28, p. 2182, 1983.

[65] M. J. McGuire, J. Addai-Mensah, and K. E. Bremmell, "The effect of polymer structure type, $\mathrm{pH}$ and shear on the interfacial chemistry, rheology and dewaterability of model iron oxide dispersions," Colloids and Surfaces A, vol. 275, no. 1-3, pp. 153160, 2006. 

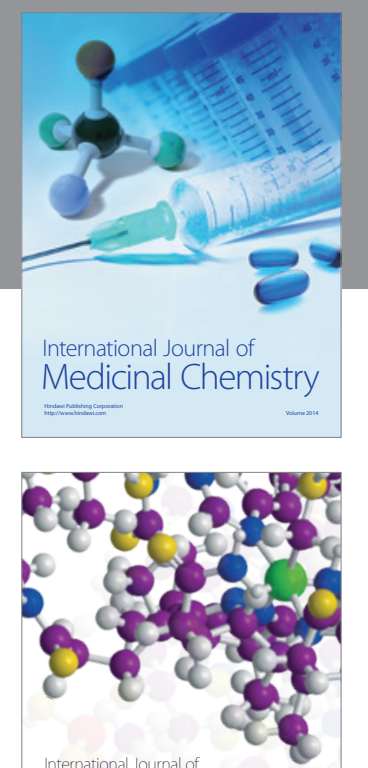

\section{Carbohydrate} Chemistry

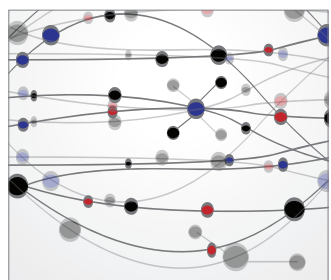

The Scientific World Journal
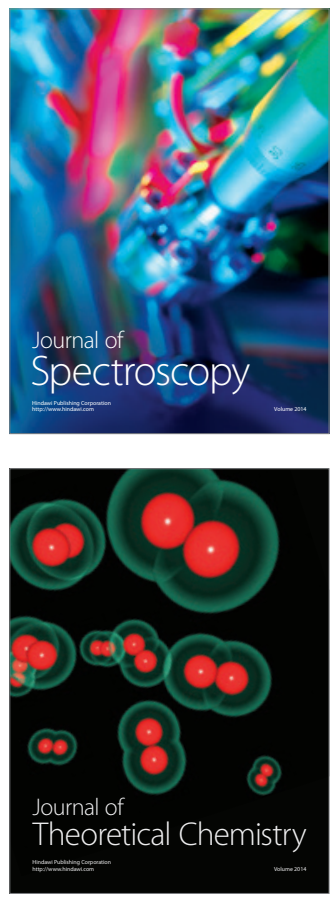
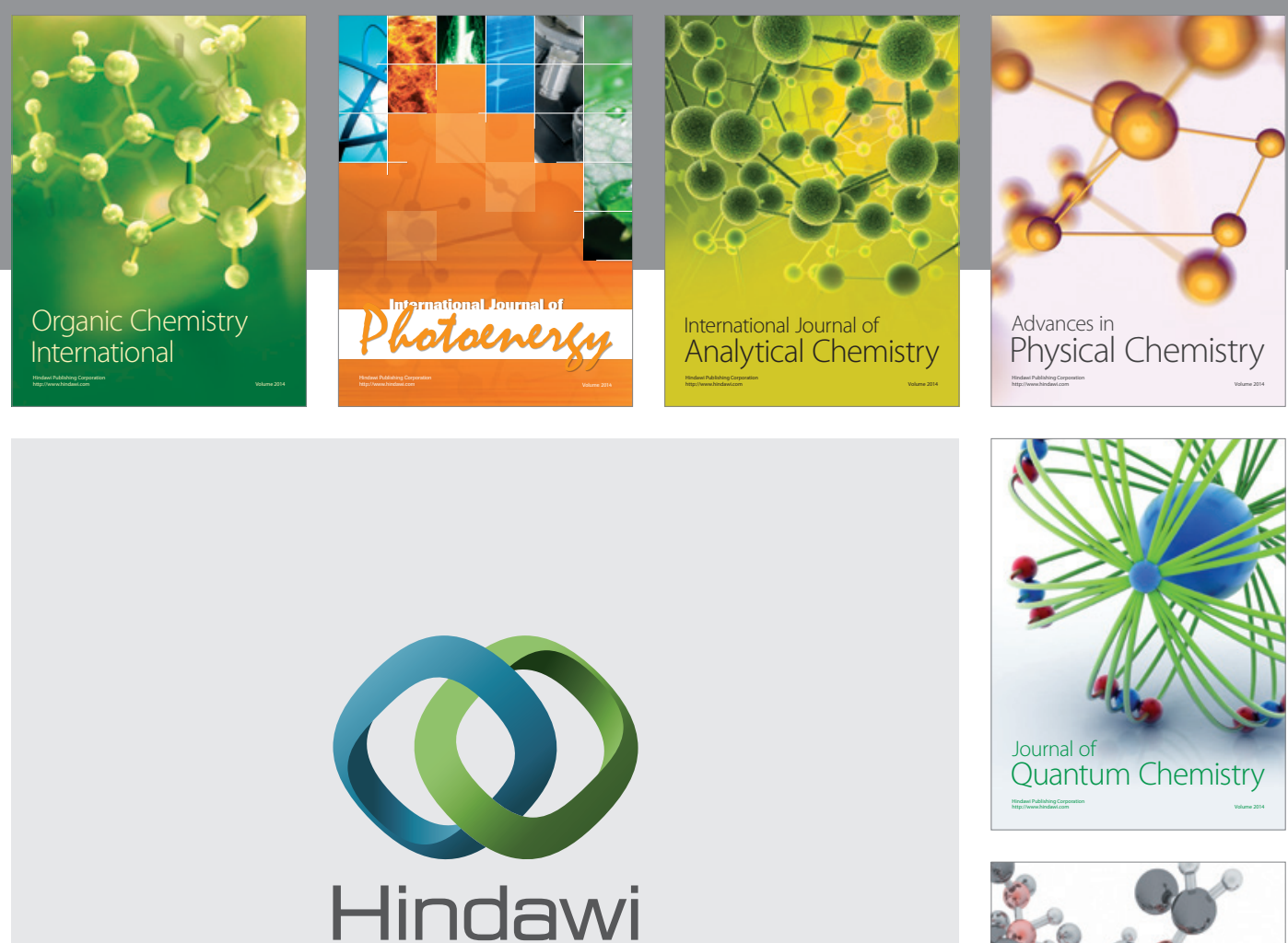

Submit your manuscripts at

http://www.hindawi.com

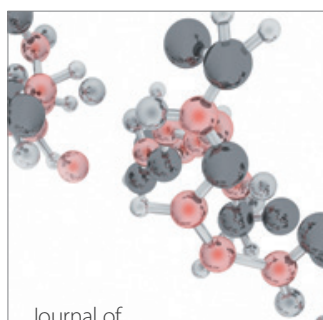

Analytical Methods

in Chemistry

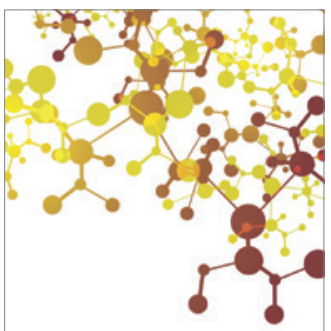

Journal of

Applied Chemistry

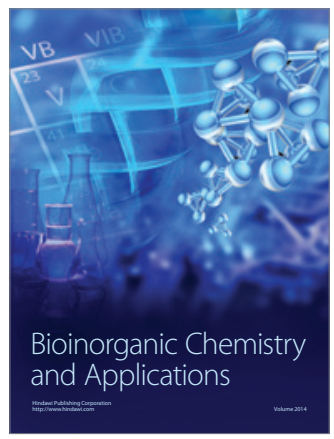

Inorganic Chemistry
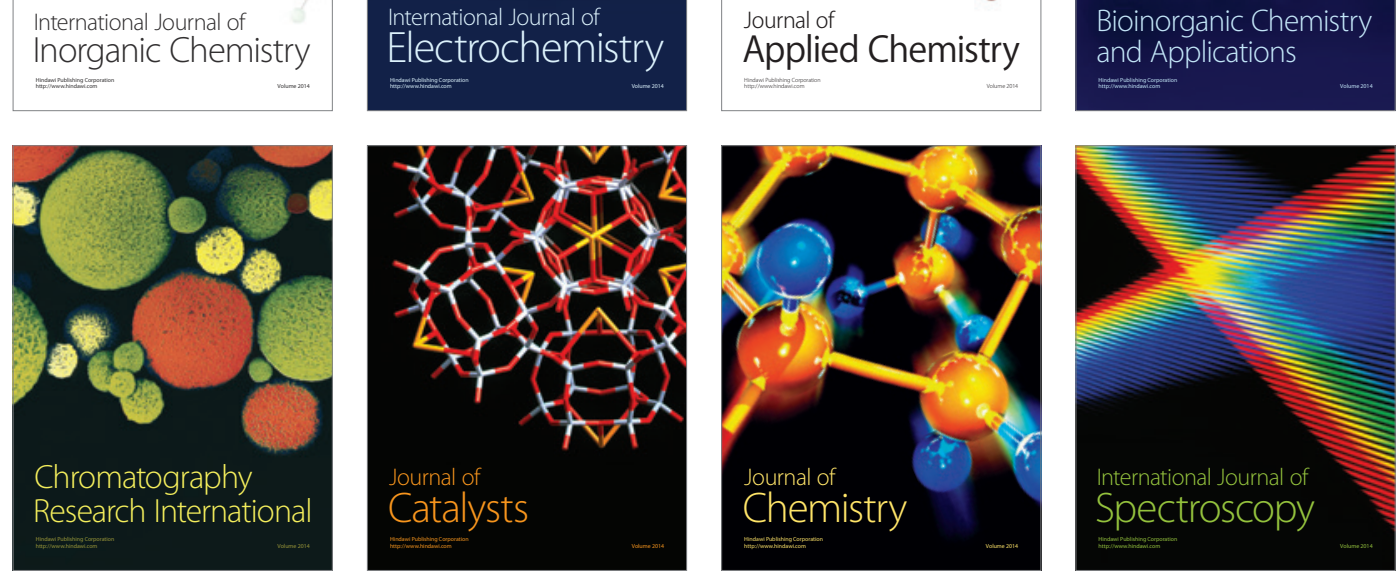